\title{
Preliminary Study of Teaching Reform on the Course of Water Supply Engineering
}

\author{
ZHANG Liping, LIU Qing, CHEN Tingting, XIANG Jun \\ School of Chemical and Environmental Engineering,China University of Mining \\ \& Technology, Beijing, China, 100083 \\ Email: haozimei77@163.com
}

\begin{abstract}
Keywords: Water supply engineering; teaching reform; comparison method; interactive method; engineering practice.

Abstract: Water supply engineering is an important branch of the comprehensive professional theory and practice in environmental engineering, municipal engineering and other related major. Through detailed analysis, there are several common problems in the course of teaching process such as few interaction and contact with other subjects, disjoint between teaching material contents and engineering practice etc. The measures such as optimizing curriculum setting, deepening teaching content, strengthening practice teaching link and reforming teaching methods are put forward in the teaching process to reach the teaching goal and cultivate higher professional personnel in colleges and universities for water supply engineering.
\end{abstract}

\section{Introduction}

With the rapid development of social economy and the acceleration of Urbanization, the water industry was developed rapidly and the related science and technology was improved constantly. It is very important to cultivate the professional talents who meet the social engineering practice ability and innovation ability. Also it is the important task of teaching reform in higher education of water supply and drainage engineering in China.

For environmental engineering, municipal engineering and other related major, water supply engineering project is a comprehensive specialized main course which is needed to pay equal attention to theory and practice. Through the study of this course, the students must master the technical principle and engineering design method of water supply network system and water supply treatment, then have the ability to engage in scientific research, technology development, process design, process design, process improvement and operation management of water supply treatment field.

At present, the traditional teaching method has various problems such as emphasizing theory and neglecting practice, teaching content unable to keep pace with the times, teaching depth can't reach the engineering practice requirements, teaching effect can't meet the teaching goal and so on. During the training of high-level personnel, the teachers have to follow the update pace of knowledge system, policies and regulations, social needs and so on. Meanwhile the teachers have to take effective teaching methods to improve the teaching effect and cultivate the high quality water supply engineering application talents.

\section{Teaching Situation and Existing Problem of Water Supply Project}

\section{Few Interaction and Contact with Other Subjects}

Water supply engineering course is a comprehensive engineering application curriculum in environmental engineering which has a strong connection and penetration with other specialized courses. Especially has a close organic link and mutual complement relationship with environmental fluid mechanics course and drainage engineering course. But in the actual teaching process, the communication among the teachers is less, which leads to the independence of each major course and does not reach the good relationships including the interaction of each course, mutual guidance and application. 
For example, the main contents of the environmental fluid mechanics course emphasis on the basic equation and model of fluid motion, molecular diffusion, follow-flow diffusion and turbulent diffusion principles and numerical solution and so on. These contents are the theoretical basis and key to learn the course of water supply engineering. Water supply engineering course combines the basic theoretical knowledge with water consumption calculation, water distribution, flow velocity and pipe diameter calculation and the location selection of the pipe network to apply in the design and calculation of the actual water distribution network.

Drainage engineering course focuses on the students to grasp the water yield, water quality characteristics, effluent quality requirements to select the appropriate treatment process, to design the size and number of treatment structure according to the process, location and site area, then based on these to select he equipment and connect the pipeline, to determine the reasonable layout according to the site of the geographical location and the surrounding hydrology meteorological conditions. All of these elements are the same as the design steps of the waterworks in the water supply engineering, and many of the treatment methods are the same and interlinked with the method of water supply engineering.

\section{Disjoint between Teaching Material Contents and Engineering Practice}

Water supply engineering is a developing and strongly applicable subject. With the rapid development of modern science and technology, new process, new technology, new equipment and new materials are emerging in practical engineering planning, design and construction. In addition, in recent years, our country attaches great importance to the municipal engineering and environmental engineering. The relevant specifications and standards are constantly updated, the national management system, institutional settings, management methods and means of related industries also have a profound change. Through market and other domestic universities investigation of the currently available teaching materials about water supply engineering, it can be found that there are very few species and the most commonly used version was published in 1999. Many contents such as a lot of new laws, regulations, standards, technical guidelines, processing technical method and processing equipment and so on are not updated and supplement in time. The teaching materials are poor effectiveness. If still use the original teaching materials, students learn some of the knowledge that has been abolished, it is very unfavorable to cultivate the innovative talents.

\section{Weakness of Practical Teaching}

Water supply engineering course in our university is open to students in environmental engineering and environmental science specialty, compared with the municipal engineering specialty, there are only 2 experiments and the class hours are only 8 , one is pure water preparation experiment/siphon filtration experiment which belongs to the demonstration experiment, only the coagulation sedimentation experiment is the student's real active hand operation. It is far below to the teaching goal of cultivating students' ability of practice, experimental design and scientific research ability.

The practice base of water supply engineering course is basically no construction, it is exactly the same practice base as drainage engineering course including some of sewage treatment plants in Beijing, this is far from the requirements of practice teaching and can not meet the requirements of the course practice, thus it can not improve the students' understanding of the actual water supply project.

\section{Unable to Reach the Teaching Objectives with Traditional Teaching Method}

The teaching objective of the course of water supply engineering is to training high level talents to meet the requirements of practical engineering, to lay a solid foundation for the national qualification examination of survey design registered utility engineer in water supply and drainage specialty. But making a general survey of teaching methods in the domestic colleges and universities, teacher teaching the theoretical knowledge is still the main traditional method, students are passively accepted theoretical knowledge. And if the students feel that the teaching content may not be practical in practice, the content is very dull and boring, meanwhile, lack of the participation and discussion opportunities, less interaction and communication between teachers and students, all these aspects may damage the enthusiasm of students and learning effects to a certain extent. The theoretical knowledge 
of teaching and the actual design case of water supply engineering are lack of convergence, students' knowledge is only applicable to the course of the final examination, it can not reach the teaching goal of cultivating practical ability talents. In the class the students seem to understand the teaching content, but students can not carry out the design and calculation of actual water supply project when it comes to the course design of water supply engineering. Students are lack of independent thinking, independent designing engineering, they can't skilled apply the theoretical knowledge to practical engineering.

\section{Teaching Reform Measures}

\section{Optimizing Curriculum to Promoting the Organic Connection between Courses}

At present, most of the domestic colleges and universities have opened water supply engineering course, drainage engineering course and water supply, drainage CAD course, courses and curriculum design, graduation design and other practical aspects for environmental engineering specialty and municipal engineering specialty. But the teaching contents of each course are independent of each other. In the course curriculum setting, teachers should communicate with each other, and combine the contents of each course together. All the related course teachers should guide curriculum design together to helping the students to apply various professional knowledge to the engineering design. In the course of successively connection among the related courses, water supply and drainage CAD course should be set up behind the theoretical courses but before the design of the courses, so that students have enough theoretical knowledge to deepen the understanding of the water supply and drainage CAD course and apply to the design and drawing of water supply and drainage engineering CAD.

\section{Deepen the Teaching Content to Achieve the Teaching Objectives}

The content of water supply engineering course is very extensive including 5 parts total 24 chapters such as water supply system in general, water transportation and distribution engineering, water intake project, water supply treatment and water cooling and circulating cooling water quality processing. Usually the number of hours of the course in colleges and universities is between 32-48 hours, it is very difficult to teach in a short period of time and let the students master all the content. Therefore, it is very necessary to make a reasonable arrangement in the choice of teaching content combined with the professional characteristics and the work of the practical requirements.

Calculation of design water consumption, calculation of pipe flow, pipe diameter and head loss calculation and hydraulic calculation of pipe network is the important and difficult point of the whole course. All these contents should be carried out in a very detailed introduction to help students understand and master the theoretical knowledge of the whole water supply engineering system. Compared with the sewage treatment method, disinfection, water softening, water desalination, water cooling and water quality treatment are commonly used in water supply treatment process which should be mainly introduced to help students fully grasp the various processing methods of different water quality. The design part of the water plant should be combined with the actual water plant project to introduce the overall system, so that students have a comprehensive understanding of the actual project.

By strengthening the construction of water works and water intake engineering practice base, adding important experiments for students to operate, strictly executing internship requirements, combining with the actual water supply engineering design, to cultivate high quality engineering and technical personnel with strong engineering ability, management ability and practical ability to meet the requirements of the enterprise. Meanwhile finally accomplish the goal that the students after graduation can quickly adapt to the job and contribute their own strength to the development of enterprises and society as soon as possible.

\section{Reforming the Teaching Method to Improve the Teaching Effect}

In order to improve students' learning interest, we can change the traditional boring, passive, one-way teaching methods. For example, adopting the comparison method to carry on the teaching, 
comparison method is to compare two or more kinds of mutual connection and mutual difference knowledge respectively through analysis, differentiation, induction, analysis of discrimination and difference, grasp the characteristics. In the water supply engineering course of teaching, the different groundwater intake structures can be compared in the water supply project to make students easy to distinguish, memory and knowledge. The performance of commonly used coagulant can be compared to help students improve their ability of identify knowledge. Various settling tanks can be compared to help students to understand and remember. Comparison method can stimulate students' thinking activities, change from passive to active, inspire the students' studying interest, strengthen the interaction between teachers and students, improve the students' ability to identify the knowledge of water supply engineering. Also we can apply the case teaching method in the course of teaching. The selection of the case can be based on the characteristics of the college and university itself. The selected case must be a typical representative, has the direct contact with theory of knowledge, and comes from practice after in-depth research, the case can not be selected by teachers' subjective conjecture and fabrication. The case teaching method can improve students' ability to apply theoretical knowledge to engineering practice. Furthermore we can make full use of the advantages of the network teaching platform to cultivate students' ability to acquire knowledge and information from the network. For example introduce http://www.civilcn.com/, http://gps.co188.com/, http://www.zhulong.com/ and other professional websites to students to download and study all kinds of water supply project related to the complete set of design specifications and drawing, and requires students to collect the corresponding application software to design and calculate.

\section{Conclusions}

The historical responsibility of water supply and drainage engineering teaching in China's higher education is to promote the scientific and technological progress and cultivate excellent water supply and drainage engineers. Through optimizing the course content, linking up the subject curriculum, updating the knowledge, reforming the traditional teaching method, introducing the network teaching resources and other measures, we can reach the ultimate goal to cultivate a large number and various types of high quality engineering and technical personnel with innovative ability, adapt to the needs of economic and social development in colleges and universities.

\section{Acknowledgements}

This work was supported by curriculum construction project (k150302) of China university of mining \& technology, Beijing

\section{References}

[1] Z.P. Wang, J.L. Zuo and Y.Z. Ren: submitted to Journal of Higher Education in Science \& Technology (2010).

[2] K.M. Yang and X.L. Yang: submitted to Journal of Higher Education (2010).

[3] M. Li, W.B. Chen, H.B. Wang, et. al: submitted to Journal of Shandong Jianzhu University(2013).

[4] Y.Q. Lu, L.W. Xu and C.C. Wei: submitted to Theory and Practice of Contemporary Education (2012).

[5] C. Yang: submitted to Curriculum Teaching (2015) .

[6] K.M. Yang and X.L. Yang: submitted to Journal of Higher Education (2013).

[7] L.P. Zhang, X.W. He and C.H. Zhang: submitted to University Education (2013) 